\title{
A Foreign Field No Longer: India, the IPL, and the Global Business of Cricket
}

Journal of Asian and African Studies 48(5) 54I-556 (c) The Author(s) 2013

Reprints and permissions: sagepub.co.uk/journalsPermissions.nav DOI: $10.1177 / 0021909613478907$ jas.sagepub.com

@SAGE

\author{
Colin Agur \\ Columbia University, USA
}

\begin{abstract}
In the past decade India has become the financing hub for cricket, a broadcaster in its own right, and an agenda-setter in the management of all forms of the game. What some commentators have called the 'Indianization' of cricket extends beyond business: it is a social, political, and cultural phenomenon. For five seasons, the Indian Premier League (IPL) has offered a glimpse of this phenomenon, prompting enthusiasm from young fans and those who stand to profit from the new league, and resistance from traditionalists. This paper discusses the material and symbolic roles the IPL has come to play in global cricket. It begins with an overview of the IPL's history, discusses how the IPL is changing the global business of cricket, and explores how the IPL is challenging the traditional culture of the sport. The paper concludes with arguments about the IPL as a grand spectacle, and a cultural phenomenon that, despite its problems, might prove its critics wrong. Throughout, the paper treats the IPL as a useful case study not only in the business of sports, but also more widely in our theoretical and empirical studies of globalization.
\end{abstract}

\section{Keywords}

Economics of sports, globalization, India, Indian Premier League, sociology of sports

Cricket is an Indian game, accidentally discovered by the British. (Ashis Nandy, 2001: 1)

In the six years since the arrival of the Indian Premier League (IPL), the global business of cricket has shifted eastward. Formally, the sport of cricket has been administered from Dubai since the International Cricket Council (ICC) moved its headquarters from London in 2005. Informally, cricket is governed by forces farther east. In the past decade India has become the financing hub for cricket, a broadcaster in its own right, and an agenda-setter in the game's global management. What some commentators have called the 'Indianization' of cricket extends beyond business. It is a social, political, and cultural phenomenon. This paper discusses the material and symbolic roles the IPL has come to play in global cricket. It begins with a brief overview of the IPL's history, then discusses how the IPL is changing the business of cricket and, finally, explores how the IPL is changing the culture of the sport. The paper concludes with arguments about the IPL as a grand 
spectacle that challenges our traditional ideas of the game, and a cultural phenomenon that, despite its problems, might prove its critics wrong.

\section{The Rapid Rise of the IPL}

Like the game of cricket itself, Twenty20 is an English invention. In 2003, after years of dwindling attendance at its county matches, the England and Wales Cricket Board (ECB) adopted a radical new idea. ${ }^{1}$ In the middle of the county cricket season teams would take a break from first-class matches (lasting three to five days in duration) and play a series of abbreviated, fast-paced matches. Limited to 20 overs (120 balls) for each team, Twenty20 quickly distinguished itself from traditional cricket. Fans flocked to these action-packed three-hour spectacles; what they saw was the birth of a faster, more aggressive, harder hitting version of cricket. Twenty 20 also proved popular with broadcasters, advertisers, and players. Each of these groups stood to profit from the new form of the game. ${ }^{2}$

In the years that followed the ECB's experiment, Twenty20 found backers elsewhere in the world. In 2004 the eight-team Pro Cricket League launched in the United States of America (USA); it lasted a single season and folded after the ICC refused to allow contracted players to join Pro Cricket, and after the league failed to sign a major broadcast deal. In 2005 two Australian first-class teams sold out the Western Australian Cricket Association (WACA) ground in Perth when they played a one-off Twenty 20 match. ${ }^{3}$ In 2006, seeking to revitalize the cricket fortunes of the West Indies, Alan Stanford held the eponymous Stanford 20/20 tournament in Antigua. The following year, the ICC held the inaugural Twenty20 World Cup in South Africa; in a thrilling final, India beat Pakistan by five runs to win the tournament. Much like India's unexpected victory in 1983 in the 50-over World Cup, the country's triumph in the Twenty20 World Cup ushered in new pride and new ambitions for the Board of Control for Cricket in India (BCCI). With the backing of the BCCI and other national bodies, Twenty 20 gained acceptance as a third sanctioned international format of the game, alongside Test and one-day matches. Initially conceived as a mid-season diversion to attract fans to county matches, Twenty 20 quickly grew into an essential money-maker and stadium-filler for domestic leagues in the world's cricketing countries.

In India, Twenty 20 gained a large following, but off-field politics led to several years of uncertainty. The country's first Twenty20 venture, the nine-team Indian Cricket League (ICL), held its first season in 2007 with the backing of Zee Telefilms. The ICL included a mixture of team types: a world XI, plus national teams representing India, Pakistan, and Bangladesh, and city-based teams in India and Pakistan. In addition to the usual challenges a new league faces in its first year, the ICL had to deal with opposition from the BCCI. In previous years, fearing a loss of its monopoly broadcast position, the BCCI had denied Zee broadcasting rights for domestic cricket matches. After being locked out of matches administered by the BCCI, Zee proposed the ICL. With its own league, Zee would enjoy unimpeded broadcast rights of ICL matches. This presented not only an immensely profitable proposition for Zee, but also a threat to the BCCI's domestic monopoly. ${ }^{4}$ Faced with this threat, the BCCI launched a legal and financial assault. Battered from the start by lawsuits and political opposition from friends of the BCCI, the ICL lasted only two seasons before folding. ${ }^{5}$ Throughout this contentious period, the BCCI's enthusiasm for Twenty 20 remained intact; what the BCCI wanted was a league under its auspices, to augment its own (already-dominant) position within India. In 2008 the BCCI launched the Indian Premier League. To cannibalize the ICL, the IPL offered higher salaries; perhaps more importantly, the BCCI offered amnesty to players who had joined the ICL in violation of their contracts with national and domestic leagues. With such an offer, and facing the possibility of bans by their national associations for playing in a 
non-sanctioned league, the remaining ICL players moved over to the BCCI-administered (and officially sanctioned) IPL. With a mass exodus of players, the ICL folded prior to its third season.

From the start the BCCI had large ambitions for the IPL, as well as good reasons to be confident. The IPL enjoyed three initial advantages: national excitement over India's early success in the Twenty 20 format, the unparalleled size of the Indian cricket market, and the shrewd scheduling of the playing season, during April and May, between the conclusion of the Ranji trophy and the onset of the annual monsoon. To introduce the league, underline its big-money status, and bring its players and uniforms into public view, the IPL televised its player auction for its inaugural season in 2008:

Theatrical, wildly hyped, and hugely lucrative, the auction was a watershed moment for the IPL and the international game. In the last month, before a ball has been bowled, the league has raised US $\$ 1.8$ billion, more than the ICC will receive for its next two World Cups. It has exposed the ICC's commercial limitations, strained relations between member states, underlined the deficiencies of the overcrowded international calendar and, by offering staggering annual salaries for six weeks' cricket, threatened the bond between players and national sides. (Kelso, 2008: para. 5)

As a new league in a sport unaccustomed to such displays of hype or capital, the IPL quickly gained attention - positive and negative - among fans and commentators. Fast, brash, and divisive, the IPL launch symbolized the ambitions of its financial backers and the BCCI.

These ambitions included a league focused on India. Like the ICL it supplanted, the IPL has a quasi-national structure, bringing players from different cricket playing countries onto commercial teams in the Indian subcontinent. But the IPL has a stronger national element than did the ICL, since it is run by the BCCI and hosted exclusively in Indian cities. In a sharp break with the pansouth Asia approach of the ICL, the IPL has no teams in surrounding countries, and has refused to admit Pakistani players. ${ }^{6}$ Part of this India-first strategy can be explained by the timing of the league's formation: the 2008 Mumbai terrorist attacks prompted fears about public security in India, and the attack a year later in Lahore on the Sri Lankan national team only reinforced the view among BCCI officials that it had more to lose than to gain by hosting matches outside India's borders. ${ }^{7}$ Now that several years have passed since these events, the IPL's exclusion of Pakistani players is more difficult to justify: it is one thing to restrict IPL matches to Indian soil so that the BCCI can retain greater control over security; it is something else to use the instability of a neighboring country as an excuse to keep its players off the field.

Although the IPL has a stronger national element than did the ICL, it would be unfair to describe the IPL simply as a national league. The IPL brings together players from the world's cricketing countries (with the notable exception of Pakistan), occupies an established place in the international cricket calendar, and operates as an ICC-sanctioned tournament. The IPL's rules on team composition reveal the IPL's dual national-global role: teams must have at least 14 Indian players in the squad and no more than 11 foreign players. In any given match they may have no more than four foreigners among the playing 11. The rules also favor young Indian talent: each team must include at least six players from the BCCI's under-22 pool. With these rules, the IPL is neither as national as the Ranji trophy, India's national first-class tournament, nor is it a fully global project. Rather, it is a distinctly Indian and cosmopolitan league.

The IPL presents a different sort of duality in its administration. The league is run by the BCCI, but its franchises are privately owned. In advance of the inaugural season in 2008, the BCCI auctioned off eight franchises for a total of US\$724 million, an average of about US\$90 million per team (ESPNCricinfo, 2008). As the IPL expanded to new cities, franchise costs soared. In 2010 the conglomerate Sahara bought the then two year-old Pune Warriors for US\$370 million, and 
Rendezvous Sports bought Kochi Tuskers Kerala for US\$330 million. As a point of comparison, two years earlier the century-old Manchester City football club changed hands for US\$330 million (Manon, 2012). But the most recent IPL team sale involved a much lower price: in late 2012, Sun Media purchased the remnants of the Deccan Chargers for US\$80 million, a considerable drop from the acquisition costs paid by previous buyers (Rao, 2012). Given the high cost of IPL franchises and the difficulties foreign owners face when making large acquisitions in India, team owners have tended to be large Indian conglomerates. Owners have included giants in infrastructure and construction (India Cements, GMR Group, UB Group), media (Sahara, the Deccan Chronicle, Sun Media), and telecommunications (Reliance). Several Bollywood stars (Shahrukh Khan, Shilpa Shetty) have purchased stakes in franchises and have become public faces for their respective teams. IPL owners provide a who's who list of (mostly) new money in India and a snapshot of India's leading industries. At the same time, the murkiness of team ownership, evidenced by the frequent use of shell companies and complex paper trails, suggests that the old game of corruption has found a new playing field (Thakur, 2010). A 2010 government report alleged that Lalit Modi, the former chairman of the IPL, held secret stakes in at least three different IPL franchises during his years as chairman (Singh and Sruthijith, 2010). As a new cash nexus in cricket, the IPL has created a new set of economic winners and losers, and challenged old assumptions about how the game should be managed.

\section{Changes in the Business of Cricket}

Since its arrival in 2008 the IPL has attracted a large fan base, both in India and, because of its sale of broadcast rights, in international markets. During its first five seasons, the IPL has established itself as a major source of revenue for the BCCI, the ICC, merchandisers, advertisers, owners, bookies, and players. In several ways, the IPL has brought changes to the global business of cricket.

Perhaps most obviously, the success of the IPL has strengthened the international position of the BCCI. In 2005 the BCCI surpassed the England and Wales Cricket Board as the richest national body in the sport; since then, it has widened the gap, and now commands substantially higher revenues than does any other national body. ${ }^{8}$ The BCCI represents a population seven times larger than that of the second most populous Test nation (Pakistan). It also represents the country where upwards of $70 \%$ of global cricket revenue is now spent (Steen, 2010: 84-88). Much of the BCCI's new clout goes beyond the game of cricket; its ascension is also the result of wider economic trends. India is still some distance from surpassing the United Kingdom (UK) as the largest economy (in nominal terms) among Test-playing nations, but its growth rate remains higher than that of the UK, and its population is growing much more rapidly. The growing fortunes of the BCCI, coupled with the economic rise of India itself, have emboldened India's cricket administrators. In recent years, other national bodies have complained that the BCCI has pressured them to adjust their domestic and international playing calendars for the benefit of the IPL. Flush with cash, the BCCI now plays a powerful - and increasingly public - role in the management of the game. In the eyes of some, it has graduated from financier to playground bully. ${ }^{9}$

In addition to strengthening the BCCI, the IPL has also brought in a new form of cricket management: privately owned, big-money professional clubs. In this respect, the IPL is an outlier: in their domestic leagues, the world's cricket-playing countries utilize county or state teams, which tend to have limited fan bases, minimal merchandising, and little media coverage outside their respective annual championship tournaments. From the West Indies to England to Australia, national cricket bodies suffer from what has been described as an 'inverted pyramid' of financing, wherein they must use profits from international matches to make ends meet at the domestic level. ${ }^{10}$ 
For many traditionalists, part of the appeal of such leagues is their un-commercial nature: they cater to fans who appreciate the rituals of multi-day matches, and continue an amateur playing tradition that dates back to the mid-19th century. During the initial years of the IPL, some observers expressed fear that the IPL would weaken, or possibly even doom, the Ranji trophy, India's national first-class championship. That has not happened. Rather, the IPL has existed in parallel with the Ranji trophy, and scheduled its playing season several months after the end of the firstclass cricket season in India. Contrary to pessimists' predictions, India now has multiple domestic leagues, each serving a different audience, and each based on a particular political economy and philosophy of cricket.

The franchise model of the IPL combines elements of the English Premier League and English county cricket. The Premier League enjoys lucrative broadcast deals, a large following in England, and networks of fans spanning the globe. While it may be slightly over-ambitious to compare itself to association football, the IPL has, in its own way, equipped its franchises for global reach. Part of this effort has involved the IPL's conscious shaping of the league's identity. Like some English county cricket teams, IPL franchises are cosmopolitan, with players drawn from different cricketplaying countries. But unlike county cricket, the IPL is not rooted in a long history. It is an upstart league that has embraced an Indian globalism from its inception. The IPL is unique in bringing (most of) the world's best cricketers together in a single short playing season, for a tournament not decided on national lines. Only the 50-over ICC World Cup exceeds the IPL for concentration of cricketing talent in a single place, and that tournament is held every four years. The IPL is an annual spectacle that lasts approximately as long (seven weeks) as the World Cup, follows a predictable schedule (round-robins commencing in early April; a final match the last Sunday in May), and fits broadcasters' schedules due to the short length of the matches.

From the start, the IPL has made broadcast a high priority. Matches are frequently played in prime time, on a pitch lit by stadium lights, using a white ball (rather than the traditional red) so players and viewers can see the ball against the night sky. Broadcasters are able to schedule matches as regular evening programming, rather than as sporadic full- or multi-day spectacles, as is the case with traditional tours by national teams. The annual schedule of the IPL provides a routinization and new ritualization of televised cricket matches, encouraging long-term advertising contracts within India and internationally. The IPL has sold broadcast rights - often for undisclosed sums - to television networks in all cricket-playing countries. When the IPL has released figures, the sums have been staggering: the IPL's publicly available broadcast revenues exceed US $\$ 1$ billion. If all contracts were counted, the total would be several times that figure (The Economist, 2011).

To reach a global audience, the IPL has downplayed the nationalism that often infuses Test and one-day international matches. Instead of drawing on tribal loyalties of nation, IPL franchises offer fans a variety of reasons to pick a favorite team. Within India, local affiliation matters: home-town players are part of teams' branding. ${ }^{11}$ For fans outside India, locality matters far less; fans are more likely to follow their favorite players' teams. For this reason, IPL teams typically include a player from most Test-playing countries, giving fans from abroad a familiar face in the team's lineup. Some teams also use their owner as part of their branding. In Kolkata, Shahrukh Khan's animated presence is part of the entertainment. In the stands, people approach him for autographs, television cameras record his reactions after key plays, and other VIPs seek a place alongside him on the mini-stage he has created for himself at Eden Gardens. With the glamour of Bollywood, a cosmopolitan mix of players from around the world, and (within India) a local identity with home-town players, IPL franchises offer a cricket spectacle that exists nowhere else. While other attempts to create club-based leagues - notably the Pro Cricket and Major League Cricket initiatives in the 
USA and the Indian Cricket League in India and Pakistan - have failed to take hold, the IPL has established itself quickly and assertively.

Beyond India, the IPL has had effects in the scheduling of the game. Now entering its sixth season, the IPL is an established part of the global cricketing calendar. Recognizing their players' desires to take part in the IPL, most Test-playing countries maintain a light schedule for their national teams in April and May. For some countries, the IPL takes away so many players that the national bodies have decided it is not worth competing during this period. ${ }^{12}$ The teams that do play Test and one-day matches during this period must accept that many of their best players will be absent, playing in India for far more money (and to larger crowds) than they could on a traditional international tour. ${ }^{13}$ This is especially problematic for England, where the playing season begins in April. English county cricket faces a particularly cruel twist of fate: having brought in the Twenty 20 format to improve its finances, county cricket may see its playing season undermined and its most popular players lured away by Twenty 20 action far from home. ${ }^{14}$ In fact, the IPL is merely the first of two related inconveniences to the county cricket schedule; the other is the Champions League, an international Twenty 20 competition $50 \%$ owned by the BCCI, that brings together the top teams in the IPL, South Africa's MiWay Challenge and Australia's Big Bash League. From 2013 onward, the Champions League is scheduled to conflict with the end of the English county cricket season, thus forcing players to choose between two leagues taking place at the same time in different countries. ${ }^{15}$ For other northern hemispheric countries (for example the 'minnows' of Ireland and the Netherlands), the IPL inspires ambivalence: on the one hand, the shortened playing season makes it more difficult to build a national team and fan base each summer. On the other hand, the IPL presents new opportunities for players from non-Test-playing countries, and its global broadcast offers players from 'minnow' countries greater audiences than they could reach at home. While the IPL looms large for national boards in northern countries, it is less of a problem for southern Testplaying countries' schedules. But these are exceptions. Increasingly, the rule is that Test and oneday international cricket grind to a halt in April and May. For national bodies, the message is clear: the IPL can lure players from around the world, outbid national bodies, and shape the international cricket calendar (Rumford, 2011; see also Stoddart, 2011).

Just as the IPL has altered the playing calendar of the game, so too has it altered the geography and geo-politics of cricket. India's growing financial and administrative dominance has helped create an unexpected winner: the United Arab Emirates (UAE). Since 2005 Dubai has been home to the ICC global office. The city is now also home to the ICC Global Cricket Academy, year-round training facilities, and a hub of expertise in sports-related media and finance. The UAE has also become the default host location for matches threatened by unrest in Pakistan. The special role the UAE has taken on in cricket - as a non-Test country with world-class facilities and the game's head office - helps avoid the tension that would develop if the ICC were located elsewhere. By moving its offices from London to Dubai, the ICC signaled the growing financial and political clout of India, as well as the comparative decline of England's influence in the game's management. ${ }^{16}$ At the same time, by choosing Dubai rather than Mumbai, the ICC sent a signal to other countries that cricket needed a neutral city for its head office. But this claim of neutrality belies the growing influence India has on the ICC. Today, the administrative center of cricket is located a mere three hours' flying time from Delhi and Mumbai. While the game is still formally administered from outside India, Dubai could hardly be closer. India has a large and growing economic presence in the Gulf and, among Test-playing countries, only Pakistan is closer to the UAE. In terms of political optics, India may be better off with this arrangement. If the ICC and BCCI were headquartered in the same city, critics from outside the country might perceive that India had captured the ICC. The UAE is distant enough from India (both geographically and culturally) that Pakistan can 
schedule its 'home' fixtures there, and multicultural enough that its government can claim not to be beholden to any of the Test-playing countries.

While the IPL has thus far integrated itself into the existing structure of international cricket, it is unclear what the future holds. The IPL is not only an alternative to traditional business models and management structures in cricket, it is also a threat. A club-based format has worked in India for a number of distinctly Indian reasons. The most obvious is India's sheer scale. It is by far the largest audience for the sport, and faces little domestic competition from other sports. This scale has allowed India to maintain two complementary domestic leagues - one that retains the game's pastoral traditions in the first-class format, and one that embraces the urban and innovative game that developed in more recent years. In a sport accustomed to strong national bodies, the arrival of rich, ambitious, and untraditional franchises is a major development, with positive and negative implications for the financial future of the game. At first glance, the IPL presents a model for other countries to follow. If other national boards are able to generate even a fraction of the Twenty20 fan bases, broadcast rights, and advertising that the IPL enjoys, they may solve the 'inverted pyramid' finance problem that has sapped national bodies for decades. ${ }^{17}$ But no other cricket-playing country has anywhere near the population of India, nor arguably is any other country as committed to one sport as India is to cricket. Now that it has established global broadcast agreements, the IPL is in a position to fight any potential competitor league. Despite its global reach, the IPL remains an Indian phenomenon, a product of Indian culture, politics, and market dynamics (Gupta, 2011).

\section{A Cultural Shift in Global Cricket}

What is happening in the IPL goes beyond business. It heralds a cultural shift in how the game is played, perceived, and followed. Perhaps most striking is the brash commerce that the IPL brings to the game. For years, fans have been accustomed to ad boards encircling the playing field and signs displayed throughout the grounds. The IPL has taken traditional cricket advertising to a new level: the bats, the stumps, and even the playing field itself feature paid advertising from sponsors. Advertising extends to the participants as well: players and even match officials, the traditional paragons of neutrality, are festooned with logos of league sponsors. When decisions are referred to the third umpire, the resulting decision is announced on television screens with the logo of a sponsor (currently Kingfisher), thus associating a brewery/airline with the impartial truth that cricket has traditionally given its officials. When teams call timeouts, broadcasters focus their cameras on the players in their respective circles. Since it is difficult to hear what the players are saying during the timeouts, there is little for the audience to do but look at the ads on the players' uniforms. With the clock counting down on a 'strategic timeout,' the audience is treated to a player discussioncum-commercial. This advertising model has proven highly lucrative for the BCCI. In its five seasons to date, the league's major sponsors have included DLF (India's largest real estate developer, which owns the league's naming rights), Hero Moto Corporation and Volkswagon (official motor sponsors), Pepsico (official beverage partner), Royal Challenge/Kingfisher (official umpires partner), Vodafone and Karbonn Mobiles (official telecom partners), and Citibank (official banking partner). These core sponsors have signed multi-year deals worth between US $\$ 10 \mathrm{~m}$ and US\$50m (Bhat and Kamath, 2012).

This culture of commercialism is related to a second major shift: the onset of a culture of speed that raises questions about what is and is not cricket. The IPL playing season lasts just seven weeks. In the same amount of time traditionally reserved for a Test tour, the IPL packs in more than 70 matches. In contrast to the traditional three to five days required for a first-class cricket match and the full day taken up by a 50-over one-day match, Twenty 20 matches are completed in less than 3.5 
hours. Gone are the lunch and tea breaks that have been a part of the cricketing ritual since firstclass matches were formalized in the mid-19th century. In place of cricket's traditional pace, the IPL has ushered in a faster and harder-hitting game that incorporates styles of play previously disparaged in the long game. ${ }^{18}$ In first-class and even one-day matches, it is common to see runrates of two to three runs per over; during its five years, the IPL average run rate has been nearly 7.5 runs per over. With short matches, faster bowling, and more aggressive batting, the IPL has turned on its head the idea that cricket is a sport of leisure. ${ }^{19}$ The IPL season that finished in May 2012 produced 709 sixes (or 'Super Sixes' in IPL parlance), an all-time high for the league. ${ }^{20}$ Together, these ingredients produce a televised spectacle that challenges the notion of cricket as an epic contest spread over multiple days. While first-class cricket remains, the newest form of the game is creating - for good or ill - a style of play more in line with other three-hour prime-time televised sports broadcasts. ${ }^{21}$

At the same time as it favors speed, the IPL also claims to emphasize certainty. Matches are broadcast using cameras set up on the perimeter of the ground, in different parts of the stadium, and even overhead - in much the same way that cameras on wires record track and field, swimming, and National Football League (NFL) football. The IPL has also been a major testing ground for Hawkeye technology. ${ }^{22}$ In the IPL, Hawkeye has served two main functions: the first is to solidify the league's credentials as incorruptible and scientific. The second has been financial. With so much at stake in team investments, sponsorships, and betting, the IPL needs to show that its officiating is beyond reproach. But the IPL's claim of scientific testing is undercut by the BCCI's refusal to embrace other, more far-reaching technological developments, such as the umpire Decision Review System (DRS). With the DRS, teams can appeal umpires' decisions to the third umpire. Supporters claim this provides accountability on umpiring and prevents mistakes from altering the course of matches. Thus far, the BCCI has been hostile to the DRS, arguing that the technology is expensive and unproven (ESPNCricinfo, 2011). But BCCI officials have left unsaid what may be the main consideration: the DRS slows down the game without generating a commercial benefit.

In addition to these debates, the IPL has also prompted questions about another type of 'certainty' in the form of inside gambling. Cricket's standard feature of play - a delivery from a bowler to a batsman - makes it especially susceptible to spot-betting. ${ }^{23}$ Often, betting syndicates offer micro bets on specific balls in specific overs. Some plays are very difficult to fix, but others invite suspicion. For example, an excessive number of no-balls is a warning sign. ${ }^{24}$ Since its inception, the IPL has faced allegations that some players participate in betting schemes. Prior to the IPL's 2012 season, in a sting operation five players were caught on tape discussing the fees they had received in exchange for manipulating the outcomes of matches. ${ }^{25}$ With Twenty 20 matches so short, each ball matters more, and it is increasingly common for matches to be decided in the final over. In the 2012 IPL season, 30\% of all matches were decided in the final over, with 18 last-over victories for batting teams, and seven chases that came down to the last ball of the match (Ugra, 2012). This is exciting for fans, but the tendency for matches to turn on a single ball makes match-fixing more tempting for players on the take, and more difficult for the IPL to prevent. With long odds for, say, calling a noball on a specific delivery in a specific over in advance of the match, betters are turning to any available information - including inside tips - to beat the oddsmakers. With audiences so large, with so many matches in so little time, and with so many permutations available for would-be betters, the IPL has generated significant gambling activity - much of it online, international, and difficult to police. Particularly in the past year, the league has attracted criticism for its failure to curtail inside betting and other forms of corruption (Vij-Aurora et al., 2012). 
This infusion of money into cricket is enabled by another, broader change: the urbanization of the game. Although cricket has pastoral origins in rural England, these origins are largely neglected by the IPL. While nearly $70 \%$ of Indians continue to live in rural areas, not a single team is located in Uttar Pradesh, India's most populous state, nor is there a team in Bihar, Orissa, or Madhya Pradesh. Ramachandra Guha has criticized this neglect, saying that, '[t]o leave out four of India's largest states - all cricket-mad, and which collectively account for close to half the country's population - must seriously disqualify the League's claim to be "Indian"” (Guha, 2012b: para. 7). Certainly, the IPL has many players and fans from rural parts of the country. But it takes place in cities and is part of an urban-centrism that prioritizes broadcast dollars over national inclusivity and produces a skewed national sporting narrative.

But this same urbanism has its supporters, notably the young people who have flocked to the IPL, attended its matches, bought its merchandise, and signed on to its social media. A striking feature of the IPL is its emphasis, not only on cities, but on making cricket a younger game. To many, cricket suffers from an image as 'boring, impossible to understand, too long, played during the week when people are at work,' and watched by a crowd typically over the age of 50 (Hopwood and Edwards, 2008: 262). To alter this image, the IPL has mandated that each team include at least six players under the age of 22, thus giving fans exposure to young, undiscovered players hoping to make a name for themselves. By scheduling its matches during evening hours, the IPL has made it easier for young fans to attend games or watch them via broadcast. The more remarkable youthoriented changes have come in the IPL's rituals of performance. Players enter the field in a manner that is less cricket than stadium rock: with music playing and fireworks exploding in the night sky, cricketers dressed in bright colors run between lines of gerbs that shower the pitch with sparks. If this sounds peculiar for a cricket match, it is by design:

A common charge levelled at the IPL is that it's not just cricket - but this works in the tournament's favour as far as the spread of its crowds goes ... At the Wankhede in Mumbai, you could have your photo taken with life-size cardboard cutouts of cricketers. Matches in Mohali, home to Kings XI Punjab, are preceded by performances by popular local artists. At Bangalore's Chinnaswamy Stadium you just might spot a popular local actor driving around the periphery of the boundary, like in a parade of floats. Then there are the cheer girls, the DJs, the fireworks ... (Bastian, 2012: para. 5)

On the pitch and in the stands, the IPL has sought to distinguish itself from the traditional colonial game. For many young Indians, the charge that the IPL is 'not just cricket' is a mark of pride. They want cricket, but they also want the celebrities, noise, and bling that have become inseparable from what happens on the field.

As the IPL adds new elements to the culture of cricket, it also challenges several traditions. The first is the narrative of cricket as a multi-day epic. The IPL has taken the basic elements of the game and compressed the playing time, with a packed annual playing season and a championship final similar to that of association football or the NFL in the USA. With an increasingly cluttered calendar, individual matches are more common and, accordingly, less special or memorable than the sporadic Test and one-day matches of the past. For a generation of young fans - in India and abroad - cricket is now a prime-time spectacle. This stands in sharp contrast to the leisure-oriented cricket that dominated until the 'Packer revolution' of the 1970s, when one-day cricket developed and the World Cup came into existence. ${ }^{26}$ Twenty 20 is fundamentally different from the long form of the game: for players and officials, a first-class match is a grueling experience, played on multiple days on a pitch where the properties evolve because of changing weather and the course of play. Luck has always played a large role in Test cricket; many a match has been decided by rain or by 
deterioration of the pitch. For its own commercial reasons, the IPL has attempted to standardize the game and reduce the element of luck. Who, after all, wants a match - and all its corresponding bets - to be decided by the quality of the pitch? This raises a question of how far the IPL will push standardization: will it mandate that boundary ropes be a certain distance from the stumps, or that ground crews produce an optimum 'IPL bounce' in the pitch? With frequent, short matches, the IPL may find that the uncertainty and the 'epic' of Test (and even one-day) cricket is bad for business. $^{27}$

The IPL is disruptive in other ways: with the exception of the BCCI, the wealth and influence of which have grown, the IPL also undermines traditional national bodies. During the early years of the IPL, the boards of England and Australia each tried to limit the league's ability to recruit players from national teams. Today, neither of these boards, to say nothing of the poorer and less influential national boards, would attempt to take on the IPL on the issue of player availability. Faced with a league that can outbid them, national bodies can do little except shift their schedules and hope that their players are not worn out or injured from the IPL season.

For many, the most troubling aspect of the IPL is the culture of money it introduces to a sport founded on Victorian ideals. Individual players have profited handsomely, and the IPL has generated an influx of cash into the BCCI. But now many are asking whether the IPL has been oversold. The league commands high broadcasting, advertising, and franchise fees, largely on the assumption that India is a highly populated, single-sport society with an insatiable appetite for all things cricket. With the IPL now entering its sixth playing season, it is possible to ask: is the hype justified? In 2010 the UK division of Brand Finance India valued the IPL at US\$4.1 billion. Its 2012 figure is a more modest US\$2.9 billion (Brand Finance, 2012). And according to the Hindu Business Line, 2012 saw a $24 \%$ drop in the average selling price of advertisements on the IPL broadcast within India (Chatterjee, 2012). Perhaps these figures are the result of new sophistication in valuation methods for an upstart cricket league. Or perhaps the IPL has been over-hyped and over-branded. While the BCCI has enjoyed a substantial windfall from the IPL, it now faces growing questions about advertisers' return on investment. Each year the IPL has experienced attrition in its advertisers, and the departure in 2012 of lead sponsor DLF suggests that the league's return on investment does not match its high costs (Burke, 2012).

Given the other financial problems the league faces - auditors have found significant problems with teams' accounting - there are legitimate reasons to question the 'Indian financial triumph' narrative of the IPL. ${ }^{28}$ While certain institutions and individuals have made fortunes, critics say this has come at a cost. Ramachandra Guha has called the IPL a 'smash-and-grab crony league' and called out prominent figures for conflict-of-interest violations:

The most egregious form of cronyism ... is the ownership of an IPL team by the current president (and former secretary) of the Board of Control for Cricket in India. It is as if Alex Ferguson was simultaneously manager of Manchester United and the president of the English Football Association. Tragically, the cronyism runs down the line. The current chairman of selectors is the brand ambassador of the team owned and run by the Board president. The famous former cricketers who cover Indian cricket on television have been consultants to the IPL. Other commentators have accepted assignments from IPL teams. To put it bluntly, their silence on this (and some other matters) has been bought. (Guha, 2012b: para. 6)

In this op-ed, Guha argues that the IPL suffers from a culture of celebrity and money worship that threatens the integrity of the game. These are stinging criticisms from India's preeminent cultural historian of cricket. If Guha and other critics are right, the IPL's business model will make Twenty20 a global game while simultaneously weakening cricket's legitimacy; something called 'cricket' will survive, but it will not be the game Guha and other Test fans follow. But is it that 
simple? Certainly the early years of the IPL have seen their share of drama, and as Guha rightly points out, the league has allowed serious problems to fester. But this good versus bad dichotomy misses a larger point: the IPL is here to stay, its fans are different from those who attend Test matches, and we can learn something by trying to envision and understand the IPL's future. The following section explores how the league is likely to evolve in the coming years, and argues that the IPL has succeeded because it taps into India's talent for the grand spectacle.

\section{Looking Ahead: Cricket as a Tamasha}

National bodies and other traditional institutions of cricket have embraced Twenty 20 because the short form of the game offers a profitable gambit. In its planning, the ECB emphasized that Twenty 20 could provide an exciting side-show that would help unprofitable county teams, draw in new viewers, and inspire some of these new viewers to explore the long form of the game. In an interview with the Sydney Morning Herald, Stuart Robinson, the Warwickshire marketing executive who helped convince the ECB to try Twenty 20 cricket, explained:

When we began researching this [Twenty 20 cricket], we didn't want the rules to be radically different, because it was intended to be a stepping stone to watch the longer versions of cricket. It was more a means to an end than an end in itself. It was your fun-sized Mars bar: a little taste of cricket that, hopefully, would get people who merely tolerated cricket - rather than those who considered themselves fans of the game - to upgrade to one-day and maybe four- and five-day cricket. (Brown, 2005: para. 3)

Ideally, Twenty20 will exist in a symbiotic commercial and cultural partnership with Test and one-day cricket, but this is no easy task. All indications suggest that Test cricket will survive, but the future of 50-over cricket is less certain. Despite early excitement in the 1970s, one-day cricket has not gained mass global appeal. It suffers from some of the same constraints as Test cricket: broadcasters dislike the irregular scheduling and length (typically eight to nine hours) of one-day matches, and advertisers are aware that, apart from the World Cup, one-day cricket reaches relatively small audiences. Thus, while the World Cup remains popular and profitable, in time the IPL may begin to supplant it - in the eyes of fans, players, and advertisers - as the premier short-format tournament. Indeed, the IPL may be the catalyst for Twenty 20 elbowing aside 50-over cricket as the mass-audience counterpart to the comparatively small-audience epic of Test cricket. ${ }^{29}$

The rapid growth of Twenty 20 - and the IPL in particular - suggests that there is a sizable market for a fast, hard-hitting, prime-time version of the game. Indians are not alone in loving Twenty20: across the world's cricket-playing countries, young fans have taken to the format in large numbers. With regular broadcasting of Twenty20 in India, the short form has become the new cricket narrative for young fans. While some of them will graduate from what Ramachandra Guha calls the 'bathtub whisky' of Twenty20 to the 'refined single malt' of Test cricket (Guha, 2012a), many others will find that the IPL gives them what they want. For good or ill, Twenty 20 and the IPL are here to stay. The Twenty 20 model arose in response to the financial challenges faced by traditional first-class cricket, and even at this early stage we can identify ways that Twenty 20 has brought new fans, new excitement, and new money to the game. To those who criticize the IPL, one might ask: how else should the game win the hearts of young people? How else should firstclass cricket sustain itself? And how else should the sport grow beyond the Commonwealth and reach a larger global audience? Rather than replace or diminish Test cricket, it seems that Twenty20 will play the complementary role first envisioned a decade ago, when the ECB introduced it as a mid-season experiment. 
From a commercial and cultural perspective, the IPL is unique in the world of Twenty20. It is a tamasha - a grand spectacle, celebration, and a participatory way-in to the game for new fans. ${ }^{30}$ The IPL has succeeded in India because it incorporates some of the elements Indians love about film - the glamour, the heroes and villains, the turn of a match on a single ball, and the possibility that the underdog can win. It is no accident that the owner of the 2012 IPL champions is also "the king of Bollywood'; in India, who understands the concept of tamasha better than Shahrukh Khan? While the IPL has yet to enjoy the same success internationally as it has in India, in its fan base and global reach, it stands alone among Twenty20 leagues. When cricket fans elsewhere in the world see the IPL, they see a young, urbanized, confident India taking the lead on a formerly colonial sport. Despite its very real problems, the IPL has become a symbol of India's global potential. Given the popularity of the sport in India, the big names involved, and the business possibilities for a prime-time short-form cricket league in India, it was probably inevitable that scandals would arise. It remains to be seen whether the IPL can curtail spot-betting and match fixing. Likewise, it is unclear whether the IPL can say no to elements of commerce that take away from the game. Of course, some of this can also be said of Test cricket, which has had its own scandals (from ball tampering to match fixing) in the past decade. The lesson here is that, for friends and foes of the IPL, it is important to see a larger picture: each of cricket's three formats plays a role. Twenty20 is a path of entry for young fans getting to know the game, and a business model for national bodies struggling to finance first-class cricket (Axford and Huggins, 2011).

Much remains unclear at this stage. For starters, will India's growing clout in management and finance also lead to dominance on the pitch? While India has performed well recently in Twenty 20 and one-day cricket, the BCCI has faced criticism that it has focused on Twenty 20 to the detriment of the country's Test fortunes. A larger question is what audiences an increasingly Indian-led sport will find in the coming years. If the IPL is any indication, the answer is younger fans, and lots of them. If we believe the optimists, the IPL will create a new and wider base for future Test fans: exposed to the short form of the game, some will find the time and inclination for the longer, richer, and more complex form of cricket. If this happens, it would represent a vision fulfilled for the ECB, which first discussed Twenty20 in 1997 and brought the format into its county season a decade ago. Looking ahead, we need not see the IPL and Test cricket as mutually opposed forces. To be sure, the IPL deserves much of the criticism it has faced for its murky finances and cozy alliances among power brokers. But these are still early days: rather than a threat to Test cricket, the IPL may simply be a new generation's idea of what cricket can also be. If the IPL brings new viewers, new passions, and new investment into the game - and in doing so, reinvigorates the sport - it seems premature to dismiss the IPL. Rather, we should watch with a critical eye and the patience of Test fans. With luck and with proper oversight, the IPL may prove its critics wrong. Perhaps, instead of cheapening an old game, the IPL will give it new life.

\section{Funding}

This research received no specific grant from any funding agency in the public, commercial or not-for-profit sectors.

\section{Notes}

1. Little academic literature examines the economics of cricket. For an assessment of English county cricket during early Twenty20 experimentation, see Paton and Cooke (2005).

2. The ECB had first discussed the possibility of 20-over cricket in 1997, when its newly-installed chairman, Lord MacLaurin, published Raising the Standard, an ambitious plan to improve the quality of play at the county level, and create a financial model that would sustain first-class cricket (see England and 
Wales Cricket Board, 1997). The idea lay dormant for five years until Stuart Robinson, a Warwickshire marketing executive, developed a concrete plan that incorporated Twenty20 as a component of the county cricket season.

3. The Western Warriors defeated the Victorian Bushrangers by eight wickets (see ESPNCricinfo, 2005).

4. For a discussion of the significance of cricket in Indian broadcasting at the time of the ICL, see Mehta (2007).

5. Rob Steen (2010) refers to this period as the 'acronym wars.'

6. The sole Pakistani player in the 2012 IPL season, Azhar Mahmood, was able to sign with Kings XI Punjab by using his British passport and declaring himself an English player.

7. This was not solely the view of the BCCI. The International Cricket Council would later strip Pakistan of its fixtures during the 2011 World Cup. In subsequent years, Pakistan's 'home' matches have been played in the United Arab Emirates (UAE).

8. The initial sale of IPL broadcast rights netted the BCCI more than US\$1 billion. See The Economist (2008).

9. For a study of public discourse and debates about the IPL, see Mehta et al. (2009).

10. For an in-depth look at the finances of county cricket and the reasons the ECB included Twenty 20 in its business model, see Kitchin (2008b).

11. In their analysis of player valuations, David Parker et al. (2008) argued that nationality was one of the main determinants of premium salaries, with Indian players enjoying consistently higher salaries than foreign players with equal (or often greater) records of performance, and home-town heroes landing the highest salaries of all. This undercuts the IPL's claim that it is a level playing field for the world's best players.

12. For a breakdown of the nationalities of players (and their respective performances), see Rajesh (2012b).

13. In 2012 this was the case for the West Indies, which played series against Australia and England, without captain Chris Gayle and several key players. The West Indies lost both series (see Hopps, 2012).

14. For a stark analysis of the financial challenges facing county cricket, see Wagg (2011).

15. The Champions League alternates between India and South Africa.

16. For a discussion of India's growing financial power at the time of the ICC's move to Dubai, see Gupta (2004).

17. To date, more than a dozen countries have set up Twenty20 leagues, hoping to cash in on the same type of success enjoyed by the IPL. Examples include: KFC T20 Big Bash League (Australia), Scotiabank National T-20 Championship (Canada), Friends Life T20 (England), East Africa Premier League (Kenya), HRV Cup (New Zealand), Faysal Bank T20 Cup (Pakistan), MiWay T20 Challenge (South Africa), Stanbic Bank T20 Series (Zimbabwe), and the eponymous Sri Lanka Premier League.

18. One example is the reverse sweep, which certain batsmen have put to effective use in Twenty 20 play. For a discussion of reverse sweep and other changes in play, see King (2011).

19. For a run rate comparison of the IPL's five seasons, see Rajesh (2012a).

20. For a complete list of 2012 playing statistics, organized by player and team, see Indian Premier League (2012).

21. For a discussion of the changing economics of leisure as shown in cricket attendance and broadcast audiences, see Paton and Cooke (2011).

22. Hawkeye is a software tool that projects the likely trajectory of a ball onto an animated version of the pitch. It has two main uses. The first is in aggregating player performance: the technology can show the balls delivered by a bowler during a match, a series, or a year; it can also reveal how well a particular batsman has played certain types of deliveries. This is especially useful in training: with the technology in use for more than a decade, coaches can draw from a large database of past matches. The second and more controversial use has been in adjudicating umpires' calls. Hawkeye is used most frequently on leg-before-wicket (LBW) calls. When the two umpires on the field refer a decision to a third umpire, he/ she watches the Hawkeye animation of the play and makes the call. Seated in a viewing room, the third umpire enjoys a zoomed-in view of the action, as well as the benefits of slow-motion and multiple replay. For audiences in the stands watching on TV or mobile devices, Hawkeye is a form of accountability on umpires, as well as a source of entertainment. 
23. Spot-betting refers to a bet on a specific play in a match, as opposed to a bet on the outcome of the entire match. In cricket, for example, a better may attempt to guess the outcome of a particular ball in a particular over of a match. For a discussion of the methods and significance of spot-betting, and the particular susceptibility of cricket to this type of gambling, see BBC News (2010).

24. A no-ball is a penalty given for an illegal delivery of the ball.

25. For more detail on the 'black money' scandal, see Basu (2012).

26. The development of 50-over cricket was itself a mixture of experimentation and accident. As Paul Kitchin (2008) writes, '[t]he first modern limited overs international was staged between England and Australia in 1971 due to poor weather conditions disrupting a scheduled Test match ... In 1975 the first limited overs World Cup was staged in England. The final, won by the West Indies, was played at Lord's. The appeal of this tournament, and increasing commercial revenue into the sport throughout the 1970s provided opportunities to develop the sport' (see Kitchin, 2008a: 70).

27. A nascent academic literature has examined the effects of the different formats of cricket on playing style (see Petersen et al., 2010).

28. The BCCI's own accountants have found problems with IPL accounting, in part because of the opacity of ownership (see Ali, 2012).

29. Cate Watson (2011) discusses the different narrative constructs of Test and Twenty20, using the radio broadcast Test Match Special.

30. For a discussion of the IPL, entertainment culture and hybridity in international sports, see Rowe and Gilmour (2009).

\section{References}

Ali QM (2012) S.B. Billimoria and Co. prick holes in IPL financial might. India Today, 10 May.

Axford B and Huggins R (2011) Cricket for people who don't like cricket: Twenty20 as expression of the cultural and media zeitgeist. Sport in Society: Cultures, Commerce, Media, Politics 14(10): 1326-1339.

Bastian N (2012) Fun for the whole family. ESPNCricinfo, 27 May. Available at: http://www.espncricinfo. com/magazine/content/story/566303.html (accessed 16 March 2013).

Basu I (2012) BCCI suspends five players for IPL spot fixing. The Times of India, 16 May.

BBC News (2010) Spot betting: How does it work? 31August. Available at: www.bbc.co.uk/news/ uk-11137067 (accessed 16 March 2013).

Bhat V and Kamath R (2012) DLF unlikely to continue with IPL title sponsorship. Business Standard, 27 April.

Brand F (2012) Indian premier league valuation 2012. Available at: www.brandfinance.com (accessed 16 March 2013).

Brown A (2005) Twenty20 an appetiser for the uninitiated, not a threat. Sydney Morning Herald, 2 February. Available at: http://www.smh.com.au/news/Cricket/Twenty20-an-appetiser-for-the-uninitiated-nota-threat/2005/02/01/1107228702401.html (accessed 16 March 2013).

Burke J (2012) Indian Premier League 2012 out to bat on an increasingly sticky wicket. The Guardian, 3 April. Chatterjee P (2012) Brands not bowled over by IPL 5. Hindu Business Line, 15 March.

England and Wales Cricket Board (1997) Raising the Standard. London: EBC.

ESPNCricinfo (2005) Sellout at WACA for Twenty20 match. 12 January.

ESPNCricinfo (2008) Big business and Bollywood grab stakes in IPL. 24 January.

ESPNCricinfo (2011) DRS technology expensive, unreliable - Niranjan Shah. 25 June.

Guha R (2012a) Interpreting Indian History through the Lens of Cricket. Lecture, Columbia University, 21 March.

Guha R (2012b) Smash-and-grab crony league. The Hindu, 25 May. Available at: http://www.thehindu.com/ opinion/lead/smashandgrab-crony-league/article3453046.ece (accessed 16 March 2013).

Gupta A (2004) The globalisation of cricket: The rise of the non-west. The International Journal of the History of Sport 21(2): 257-276. 
Gupta A (2011) The IPL and Indian domination of global cricket. Sport in Society: Cultures, Commerce, Media, Society 14(10): 1316-1325.

Hopps D (2012) The case for an IPL window. ESPNCricinfo, 31 May.

Hopwood M and Edwards A (2008) The game we love, evolved: Cricket in the 21st century. In: ChadwickSandArthurD(eds)InternationalCasesinthe BusinessofSport.Oxford:Butterworth-Heinemann/ Elsevier, 257-269.

Indian Premier League (2012) IPL 2012 stats. Available at: http://iplt20.com/stats/2012 (accessed 16 March 2013).

Kelso P (2008) After spending $\$ 42$ million on players in a frenzied day, cricket's new princes take aim at a global fan base. The Guardian, 21 February. Available at: http://www.guardian.co.uk/sport/2008/feb/21/ cricket.indianpremierleague1 (accessed 16 March 2013).

King A (2011) The reverse sweep. Sport in Society: Cultures, Commerce, Media, Politics 14(10): 1395-1406.

Kitchin P (2008a) The development of limited overs cricket: London's loss of power. London Journal of Tourism, Sport and Creative Industries 1(2): 70-75.

Kitchin P (2008b) Twenty-20 and English domestic cricket. In: Chadwick S and Arthur D (eds) International Cases in the Business of Sport. Oxford: Butterworth-Heinemann/Elsevier, 101-113.

Manon S (2012) India's cricket: IPL's legacy as season five begins. BBC News, 3 April. Available at: http:// www.bbc.co.uk/news/world-asia-india-17587612 (accessed 16 March 2013).

Mehta N (2007) The Great Indian News Trick: Satellite Television, Cricketisation and Indianisation. Paper presented at the One-Day Seminar on International Cricket at the University of London, 2 March.

Mehta N, Gemmell Jon and Malcolm Dominic (2009) 'Bombay sport exchange': Cricket, globalization, and the future. Sport in Society: Cultures, Commerce, Media, Politics 12(4-5): 694-707.

Nandy A (2001) The Tao of Cricket. New York: Oxford University Press.

Parker D, Burns P and Natarajan H (2008) Player valuations in the Indian premier league. Frontier Economics Oct 2008: 1-17.

Paton D and Cooke A (2005) Attendance at country cricket: An economic analysis. Journal of Sports Economics 6(1): 24-45.

Paton D and Cooke A (2011) The changing demands of leisure time: The emergence of Twenty20 cricket. In: Cameron S (ed.) Handbook on the Economics of Leisure. Cheltenham: Edward Elgar Publishing, 381-406.

Petersen CJ, Pyne D, Dawson B et al. (2010) Movement patterns in cricket vary by both position and game format. Journal of Sports Sciences 28(1): 45-52.

Rajesh S (2012a) Numbers game: The IPL's most and least productive overs. ESPNCricinfo, 4 May.

Rajesh S (2012b) The overseas factor in the IPL. ESPNCricinfo, 11 May.

Rao KS (2012) Sun TV buys IPL's Hyderabad franchise for Rs 425 crore. Times of India, 26 October.

Rowe D and Gilmour C (2009) Global sport: Where Wembley way meets Bollywood boulevard. Continuum: Journal of Media and Cultural Studies 23(2): 171-182.

Rumford C (2011) Twenty20, global disembedding, and the rise of the 'portfolio player'. Sport in Society: Cultures, Commerce, Media, Politics 14(10): 1358-1368.

Singh R and Sruthijith KK (2010) Lalit Modi involved in betting, murky deals. The Times of India, 19 April.

Steen R (2010) The economics and Indianisation of contemporary cricket. In: Rumford C and Wagg S (eds) Cricket and Globalization. Newcastle: Cambridge Scholars Publishing, 103-121.

Stoddart B(2011) Game for hire: Twenty20 and the new cricket mercenary. Sport in Society: Cultures, Commerce, Media, Politics 14(10): 1421-1427.

Thakur P (2010) IPL money trail leads to British Virgin Islands. The Times of India, 13 October.

The Economist (2008) Jiminy cricket. 31 January.

The Economist (2011) Go fetch that. 13 January.

Ugra S (2012) The IPL earns its cricket cred. ESPNCricinfo, 28 May.

Vij-Aurora B et al. (2012) IPL: The dirty picture. India Today, 4 June. 
Wagg S (2011) 'The four-day game doesn't pay the bills': Leicestershire, 2010-11: A case study in the contemporary political economy of cricket. Sport in Society: Cultures, Commerce, Media, Politics 14(10): $1407-1420$.

Watson C (2011) Test match special, Twenty20, and the future of cricket. Sport and Society: Cultures, Commerce, Media, Politics 14(10): 1383-1394.

\section{Author biography}

Colin Agur is a PhD candidate in Communications at Columbia University and a Visiting Fellow at the Yale Information Society Project. 